\author{
Yayah Robiatul \\ Adawiyah $^{1}$ \\ Istibsyaroh $^{2}$ \\ Aulia Nuriyatir Rofi'ah ${ }^{3}$
}

\section{PEMBELAJARAN BAHASA ARAB BERBASIS MULTIKULTURALISME AGAMA MELALUI METODE HYPNOTEACHING}

\begin{abstract}
Abstrak
Berdasarkan pengamatan dan study lapangan oleh penulis pada bulan November 2020 di Institut Dirosat Islamiyah Al- Amien Fakultas Ushuluddin bahwa dari beberapa mahasiswa pada tahun sebelumnya masih mengalami kesulitan dalam berbahasa khususnya yang berkaitan dengan bahasa Arab pada materi jurusan mereka yang berhubungan dengan hal keagamaan. Problematika ini menurut hemat penulis bersumber pada sistem terpisah dalam pembelajaran bahasa Arab pada materi mereka. Selain itu kandungan isi materi bahasa pada materi jurusan mereka yang berhubungan dengan hal keagamaan masih banyak yang berbasis monokultural. Dari hasil tahap analisis mahasiswa/i membutuhkan bahan ajar dan metode penunjang lain yang lebih interaktif dan inovatif yang mana bisa membantu mengatasi kesulitan mereka dalam pembelajaran bahasa Arab. Berangkat dari kondisi dalam proses belajar mengajar tersebut maka penulis tertarik untuk meneliti bagaimana proses Institut Dirosat Islamiyah Al- Amien Fakultas Ushuluddin menerapkan pembelajaran bahasa Arab berbasis multikulturalisme agama melalui metode hypnoteaching sebagai solusi dari permasalahan pembelajaran bahasa Arab sebelumnya. Penelitian ini menggunakan metode penelitian kualitatif dimana penelitian kualitatif sebagai metode ilmiah. Teknik pengumpulan data dalam penelitian kualitatif ini adalah dengan melakukan observasi, wawancara, dan studi dokumentasi. Penulis menggunakan teknik sampling purposive untuk menentukan informan dalam penelitian ini. Hasil penelitian menunjukkan bahwa implementasi pembelajaran bahasa Arab berbasis multikulturalisme agama melalui metode hypnoteaching pada Fakultas Ushuluddin pengajaran materi bahasa Arab terpadu ini menuntut mahasiswa/i untuk mempraktekkan keterampilan-keterampilan dalam rangkaian yang tidak terputus-putus. Sehingga pada akhirnya pengajaran bahasa akan menjadi aktif dan komunikatif. Sedangkan kelebihan dari implementasi integrasi tersebut terlihat pada segi kontinuitas,Input sebelum Output, realistik, kritis, analitis, dan ilmiah yang membuat pikiran mahasiswa/i menjadi lebih rileks, nyaman, meditatif, terkendali, dan fokus dengan metode hypnoteaching. Sedangkan kekurangannya adalah masih ditemukan urutan pengajaran keterampilan bahasa yang masih kurang sistematis dalam urutannya juga langkah metode hypnoteaching yang kurang lengkap yang membuat cakupan tujuan dari metode hypnoteaching tersebut kurang lengkap dalam mencetak gol yang dituju.
\end{abstract}

Kata Kunci: Pembelajaran Bahasa Arab, Multikulturalisme Agama, Metode Hypnoteaching

\title{
Abstract
}

Based on observations and field studies by the author in November 2020 at the Dirosat Islamiyah Al-Amien Institute at the Faculty of Ushuluddin, some students in the previous year still experienced difficulties in language, especially those related to Arabic in their department's material related to religious matters. This problem, according to the author's opinion, comes from a separate system in learning Arabic in their material. In addition, the content of language material in their department's materials related to religious matters is still mostly monocultural based. From the results of the analysis stage, students need teaching materials and other supporting methods that are more interactive and innovative which can help overcome their

\footnotetext{
${ }^{1,2,3}$ Program Studi Pendidikan Bahasa Arab, Fakultas Agama Islam, Universitas Nurul Jadid
} Alamat email : ya2hsoebandi@gmail.com 
difficulties in learning Arabic. Departing from the conditions in the teaching and learning process, the authors are interested in examining how the process of the Al-Amien Dirosat Islamiyah Institute at the Faculty of Ushuluddin applies Arabic language learning based on religious multiculturalism through the hypnoteaching method as a solution to the problems of previous Arabic learning. This study uses qualitative research methods where qualitative research is a scientific method. The technique of collecting data in this qualitative research is by making observations, interviews, and documentation studies. The author uses purposive sampling technique to determine the informants in this study. The results showed that the implementation of Arabic language learning based on religious multiculturalism through the hypnoteaching method at the Faculty of Ushuluddin, teaching integrated Arabic material requires students to practice skills in a series. that is not intermittent. So that in the end language teaching will be active and communicative. While the advantages of implementing this integration can be seen in the aspect of continuity, input before output, realistic, critical, analytical, and scientific which makes students' minds more relaxed, comfortable, meditative, controlled, and focused with the hypnoteaching method. While the drawback is that there is still a sequence of teaching language skills that is still less systematic in the sequence as well as incomplete hypnoteaching method steps which make the scope of the objectives of the hypnoteaching method incomplete in scoring the intended goals.

Keywords: Arabic learning, Religious Multiculturalism, Hypnoteaching Method

\section{PENDAHULUAN}

Pengajaran bahasa Arab sangat menarik sekali untuk dikaji ulang. Bukan saja karena fungsi dan esensinya bagi kehidupan komunikasi Islam, tapi karena sifatnya yang berada di tengahtengah tradisi kependidikan yang sedang berlangsung dewasa ini memerlukan berbagai inovasi, sebagai konsekuensi logis berkembangnya sains dan teknologi. Perkembangan ilmu pengetahuan dan teknologi yang begitu pesat bagi kehidupan manusia, maka diperlukan adanya upaya pada teknisi pengajaran bahasa.

Berdasarkan pengamatan dan study pendahuluan lapangan oleh penulis pada bulan November 2020 di Institut Dirosat Islamiyah Al- Amien pada Fakultas Ushuluddin yang berada di bawah naungan Pondok Pesantren Al-Amien Prenduan Sumenep Madura bahwa dari beberapa mahasiswa pada tahun sebelumnya masih mengalami kesulitan dalam berbahasa khususnya yang berkaitan dengan bahasa pada materi jurusan mereka yang berhubungan dengan hal keagamaan. Dalam perkembangan lembaga pendidikan Indonesia, ada dua sistem yang dikenal dalam mengajarkan unsur-unsur bahasa dan keterampilan-keterampilan berbahasa tersebut, yaitu sistem terpisah-pisah dan sistem terpadu. Sistem terpisah adalah pembelajaran bahasa yang dilakukan secara terpisah yang memisahkan empat kemampuan berbahasa. Sementara sistem terpadu menganggap bahwa bahasa adalah satu kesatuan terpadu dan terikat, bukan terpisah-pisah. Pembelajaran terpadu harus dilakukan secara seimbang antara empat kemahiran berbahasa. Metode ini muncul sebagai respon terhadap kegagalan sistem terpisah dalam menerapkan metodenya. Pengikut aliran sistem terpadu mengkritik bahwa metode terpisah memiliki banyak kekurangan dilihat sudut pandang filsafat bahasa, baik dari segi penerapan, pembelajaran, maupun fungsinya. Mereka menganggap kekurangan terbesar sparated system adalah pengajaran bahasa yang dilakukan secara terpisah-pisah antara kemampuan berbahasa satu dengan yang lainnya.

Selain itu kandungan isi materi bahasa pada materi jurusan mereka yang berhubungan dengan hal keagamaan masih banyak yang berbasis monokultural, yang ditakutkan nantinya akan menjadi akar dalam keyakinan keagamaan yang fundamental, eksklusif dan diskriminatif sehingga konflik sosial sulit diatasi, dengan ini perlunya dihadirkan basis multikultural sebagai solusinya. James A. Banks, berpendapat tentang pendidikan multikultural merupakan konsep, ide atau falsafah sebagai suatu rangkaian kepercayaan (set of believe) dan penjelasan yang mengakui dan menilai pentingnya keragaman budaya dan etnis didalam membentuk gaya hidup, pengalaman sosial, identitas pribadi, peluang dalam pendidikan sebagai individu, kelompok ataupun warga negara. Jadi, pendidikan multikultural adalah usaha sadar untuk mengembangkan kepribadian tentang berbagai macam status sosial, ras, suku, agama agar tercipta kepribadian yang cerdas dalam menghadapi masalah-masalah keberagaman budaya. 
Pengajaran materi dengan sistem klasik harus mulai ditinggalkan, proses pendidikan bukan lagi memberikan stimulus, melainkan usaha mengembangkan potensi yang dimiliki. Di sini, peserta didik tidak lagi dianggap sebagai objek, tetapi sebagai subjek belajar yang harus mencari dan mengontruksi pengetahuannya sendiri. Pandangan inilah yang menyebabkan perubahan paradigma pembelajaran dari teacher centered menjadi student centered. Peserta didik dituntut untuk berpikir secara logis, analitis, dan kritis dalam mencari, menyelidiki, dan menemukan jawaban atas masalah yang dipertanyakan tersebut.

Berangkat dari kondisi dalam proses belajar mengajar tersebut maka penulis tertarik untuk meneliti bagaimana proses Institut Dirosat Islamiyah Al- Amien Fakultas Ushuluddin menerapkan pembelajaran bahasa Arab sistem terpadu berbasis multikulturalisme agama melalui metode hypnoteaching sebagai solusi dari permasalahan pembelajaran bahasa Arab sebelumnya. metode hypnoteaching adalah usaha untuk menghipnosis atau mensugesti anak didik supaya menjadi lebih baik dan prestasinya meningkat. Hypnoteaching bisa dikatakan sebagai improvisasi dari sebuah metode pembelajaran. Metode ini mencoba hadir dengan memberikan sebuah pendekatan konseptual baru di bidang pendidikan dan pembinaan. Perlu diketahui bahwa hypnoteaching hanya bermain dalam tatanan pikiran alam bawah sadar seseorang. Melalui penguasaan hypnoteaching, para guru akan bisa memahami pola kerja otak yang sebenarnya.

Dalam hypnoteaching guru bertindak sebagai penghipnotis, sedangkan anak didik berperan sebagai suyet atau orang yang dihipnotis. Dalam pembelajaran, sebenarnya guru tidak perlu menidurkan anak didiknya ketika memberikan sugesti. Guru cukup menggunakan bahasa yang persuasif dan mudah dipahami sebagai alat komunikasi yang sesuai dengan harapan anak didik.

Dengan begitu, peserta didik tidak merasa tegang dalam kegiatan belajar mengajar dalam kelas. Peserta didik juga akan merasa nyaman dan enjoy dengan guru dan materi yang diberikan olehnya.

\section{METODE}

Metode penelitian ini menggunakan pendekatan penelitian kualitatif dimana penelitian kualitatif sebagai metode ilmiah sering digunakan dan dilaksanakan oleh sekelompok peneliti dalam bidang ilmu social, termasuk juga ilmu pendidikan. Pada penelitian ini peneliti membuat suatu gambaran kompleks, meneliti kata-kata, laporan terinci dari pandangan responden dan melakukan study pada situasi yang alami. Penelitian ini dilakukan di Institut Dirosat Islamiyah Al- Amien (IDIA) fakultas Ushuluddin yang merupakan perguruan tinggi waqaf yang berada di bawah naungan Pondok Pesantren Al-Amien Prenduan Sumenep Madura. Teknik pengumpulan data dalam penelitian kualitatif ini adalah dengan melakukan observasi, wawancara, dan studi dokumentasi. Penulis menggunakan teknik sampling purposive untuk menentukan informan dalam penelitian ini. Teknik sampling purposive yaitu cara menentukan informan dengan memilih informan sesuai dengan kriteria dan kebutuhan penulis dalam penelitian ini.

\section{HASIL DAN PEMBAHASAN}

\section{Implementasi Pembelajaran Bahasa Arab Berbasis Multikulturalisme Agama} Melalui Metode Hypnoteaching

Hasil dari analisis penelitian yang didapat dari hasil observasi, wawancara dan studi dokumentsi, peneliti mendadaptkan hasil bahwasanya para dosen dalam praktek implementasi pembelajaran bahasa Arab berbasis multikulturalisme agama melalui metode Hypnoteaching di Institut Dirosat Islamiyah Al- Amien Fakultas Ushuluddin memulai dengan penyusunan secara sistematis dan menarik materi ajar yang mencakup isi materi, metode, dan evaluasi yang dapat digunakan dalam pembelajaran terbimbing maupun secara mandiri untuk mencapai indikator yang telah ditetapkan dengan sistem terpadu seimbang antara empat kemahiran berbahasa. Kandungan isi materi bahasa pada pengembangan materi ini bersandar pada basis multikulturalisme agama sebagai pencabut akar dalam keyakinan keagamaan yang fundamental, eksklusif dan diskriminatif.

Pengajaran bahasa Arab diarahkan pada penguasaan linguistic competence, yaitu bahasa sebagai alat komunikasi. Oleh karena itu, dari segi pendekatan, pengajaran materi bahasa Arab ini menggunakan pendekatan kegiatan yang seimbang 'a balanced activities approach', yaitu sebuah pendekatan dalam pengajaran bahasa yang melihat tugas pengajar adalah memastikan 
bahwa para mahasiswa/i mendapatkan aktifitas kebahasaan yang bervariasi yang mengarahkan mahasiswa/i untuk belajar dan memperoleh (acquistion) keterampilan berbahasa.

Sebagai gambaran berikut ini disajikan sebuah model sederhana pengajaran materi bahasa Arab terpadu:

Tabel 1. Model Pengajaran Bahasa Arab Berbasis Multikulturalisme Agama Melalui Metode Hypnoteaching

\begin{tabular}{|c|c|c|}
\hline No & Kegiatan & $\begin{array}{l}\text { Keterampilan } \\
\text { Yang } \\
\text { Di praktikkan }\end{array}$ \\
\hline 1. & 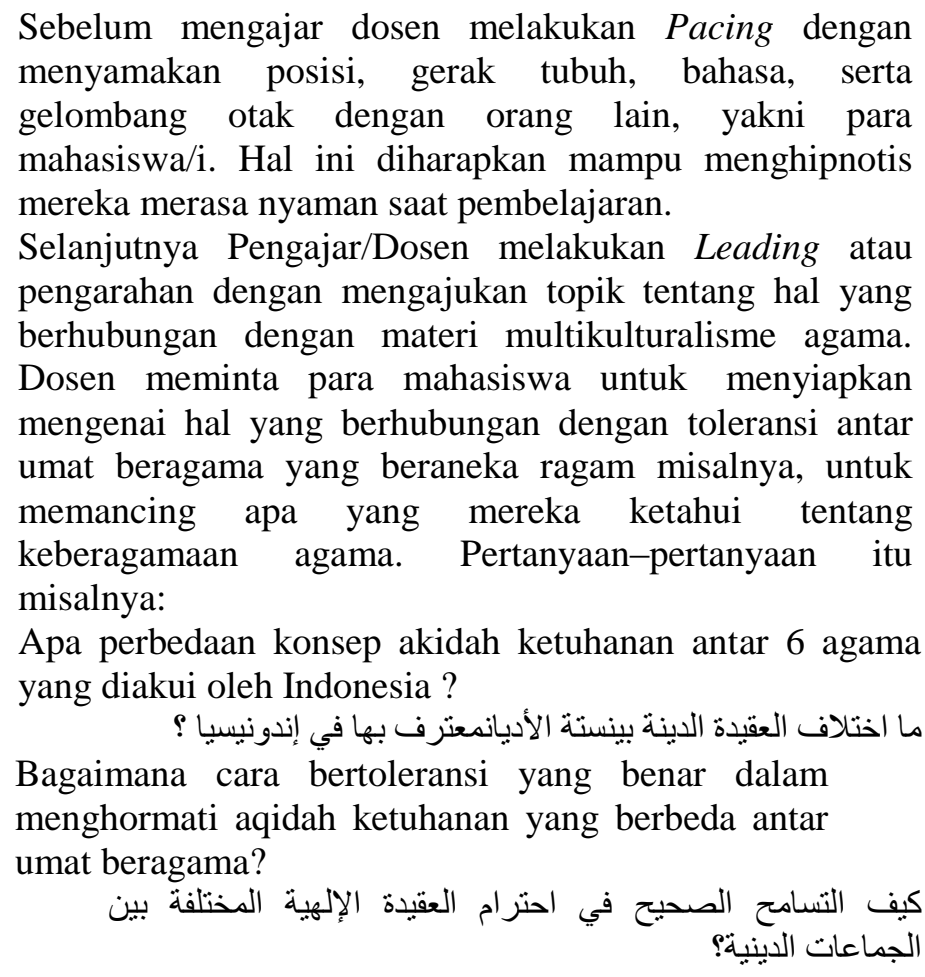 & $\begin{array}{l}\text { Keterampilan } \\
\text { Berbicara }\end{array}$ \\
\hline 2. & $\begin{array}{l}\text { Mahasiswa/i membaca paragraf deskriptif singkat tentang } \\
\text { toleransiantar umat beragama untuk menemukan jawaban } \\
\text { pertanyaan aktifitas no } 1 \text { pada buku pedoman yang } \\
\text { digunakan di Institut Dirosat Islamiyah Al-amien Fakultas } \\
\text { Ushuluddin. }\end{array}$ & $\begin{array}{l}\text { Keterampilan } \\
\text { Membaca }\end{array}$ \\
\hline 3. & $\begin{array}{l}\text { Mahasiswa/i membandingkan berapa banyak jawaban } \\
\text { mereka yang benar atas pertanyaan yang diajukan dan } \\
\text { berapa banyak informasi yang baru bagi mereka. }\end{array}$ & $\begin{array}{l}\text { Keterampilan } \\
\text { Berbicara dan } \\
\text { Mendengar }\end{array}$ \\
\hline 4. & $\begin{array}{l}\text { Mahasiswa/i belajar mandiri, berpasangan atau kelompok } \\
\text { untuk membahas topik yang telah ditentukan oleh dosen } \\
\text { pada buku pedoman. Mereka berdiskusi dan membuat } \\
\text { catatan jawaban atas pertanyaan-pertanyaan tentang } \\
\text { keberagaman agama. }\end{array}$ & $\begin{array}{l}\text { Keterampilan } \\
\text { Berbicara dan } \\
\text { Menulis }\end{array}$ \\
\hline 5. & $\begin{array}{l}\text { Mahasiwa/i menulis paragraf deskriptif singkat } \\
\text { tentang toleransi antar umat beragama yang telah } \\
\text { ditentukan berdasarkan informasi yang telah mereka } \\
\text { catat. }\end{array}$ & $\begin{array}{l}\text { Keterampilan } \\
\text { Menulis }\end{array}$ \\
\hline
\end{tabular}




\begin{tabular}{|l|l|l|}
\hline $6 . \quad \begin{array}{l}\text { Mahasiwa/i membaca catatan yang telah dicatat dengan } \\
\text { perwakilan dari masing-masing kelompok dan anggota } \\
\text { yang lainnya mendengarkan dan mengoreksi jika ada }\end{array}$ & $\begin{array}{l}\text { Keterampilan } \\
\text { Membaca dan } \\
\text { yang salah dari catatan yang dibaca. } \\
\text { Diakhir dosen memberikan kesimpulan dan masukan dari } \\
\text { tiap hasil tugas perkelompok juga memberikan reward } \\
\text { berupa pujian bagi keaktifan mereka dan kata-kata } \\
\text { motivasi. }\end{array}$ \\
\hline
\end{tabular}

Selain itu dari hasil analisis penelitian, peneliti menemukan dosen yang melakukan pengembangan bahan ajar penunjang multimedia interaktif dengan basis aplikasi android yang berisi materi pembelajaran Nahwu bagi mahasiswa yang belum banyak mengerti hal yang berkaitan dengan kaidah Nahwu.

Berikut adalah bentuk desain pengembangan bahan ajar multimedia interaktif berbasis aplikasi android dengan pendekatan hypnoteaching dalam pembelajaran nahwu untuk para mahasiswa pemula di tingkat dasar ilmu Nahwu :

Tabel 2. Desain Bahan Ajar Nahwu Penunjang Pengajaran Bahasa Arab Sistem Terpadu Berbasis Multikulturalisme Agama Melalui Metode Hypnoteaching

\begin{tabular}{|l|l|}
\hline DESAIN BAHAN AJAR & $\begin{array}{l}\text { KARAKTERISTIK } \\
\text { (APLIKASI ANDROID) }\end{array}$ \\
\hline
\end{tabular}




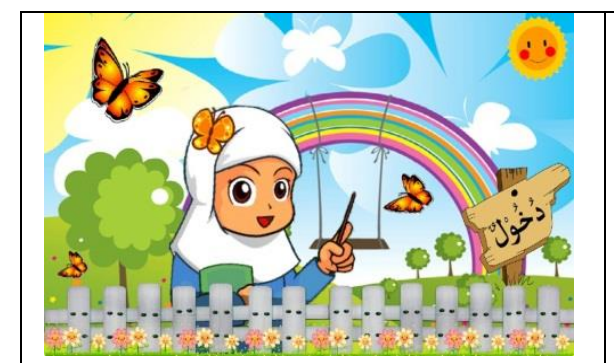

(Layout Sambutan Awal)

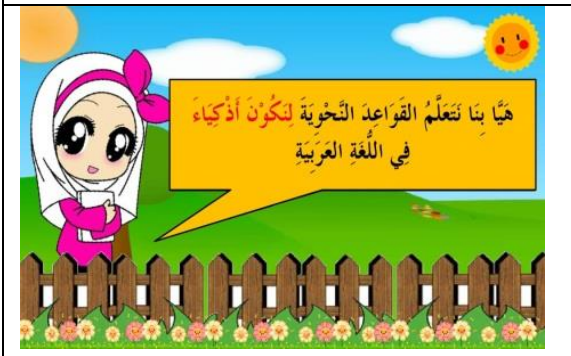

(Layout kata positif)

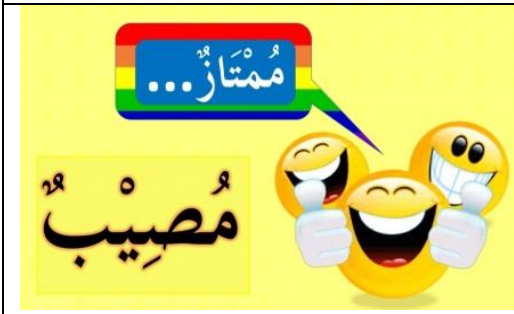

(Layout Kata Pujian)

\section{Leading}

Leading berarti memimpin atau mengarahkan. Setelah melakukan pacing, peserta didik akan merasa nyaman dengan suasana pembelajaran yang berlangsung.

Dalam desain ini dirancang dengan memberikan kalimat arahan pada kalimat sambutan di layout awal sebelum menuju HomeLayout Pilihan Materi. Kalimat tersebut adalah :

"أهلا وسهلا في تعلم النحو الميسّر وينبغي أن يكون التعبير

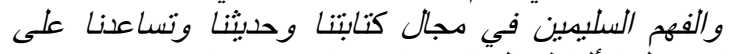
استعمال الألفاظو والتراكيب /ستعمالا صحيحا".

\section{Menggunakan kata-kata positif}

Penggunaan kata positif ini sesuai dengan cara kerja pikiran bawah sadar yang tidak mau menerima kata-kata negatif. Kata-kata yang positif dari guru dapat membuat peserta didik menjadi lebih percaya diri dalam menerima materi yang diberikan.

Dalam desain ini dirancang dengan memberikan kata-kata positif pada layout kata postif sebelum menuju layout materi. Kata-kata positif tersebut adalah :

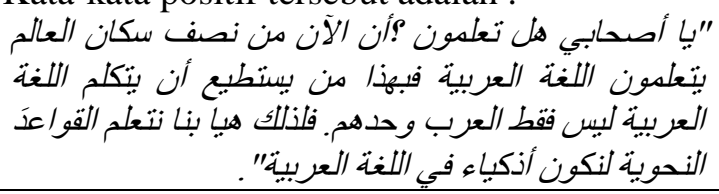

\section{Memberikan Pujian}

Setelah materi diajarkan maka dalam evaluasinya guru harus memberikan apresiasi kepada peserta didik yang mampu menguasai pelajaran dengan memujinya. Hal ini karena pujian bisa menambah rasa percaya diri dan keyakinan peserta didik.

Dalam desain ini dirancang dengan memberikan kata pujian bagi yang bisa menjawab pertanyaan materi dalam aplikasi ini. Kata pujian tersebut adalah :

\section{Modeling}

Modeling merupakan proses pemberian teladan atau contoh melalui ucapan dan prilaku yang konsisten.

Dalam desain ini dirancang dengan memberikan teladan membaca sebagai perilaku yang harus diteladani melalui ucapan kata ajakan dan perintah yang disimbolkan dengan anak perempuan sedang membawa buku sebagai model teladan. Kata dalam modeling tersebut adalah :

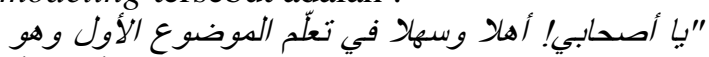

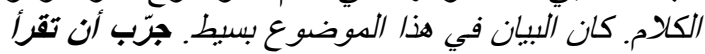

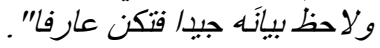




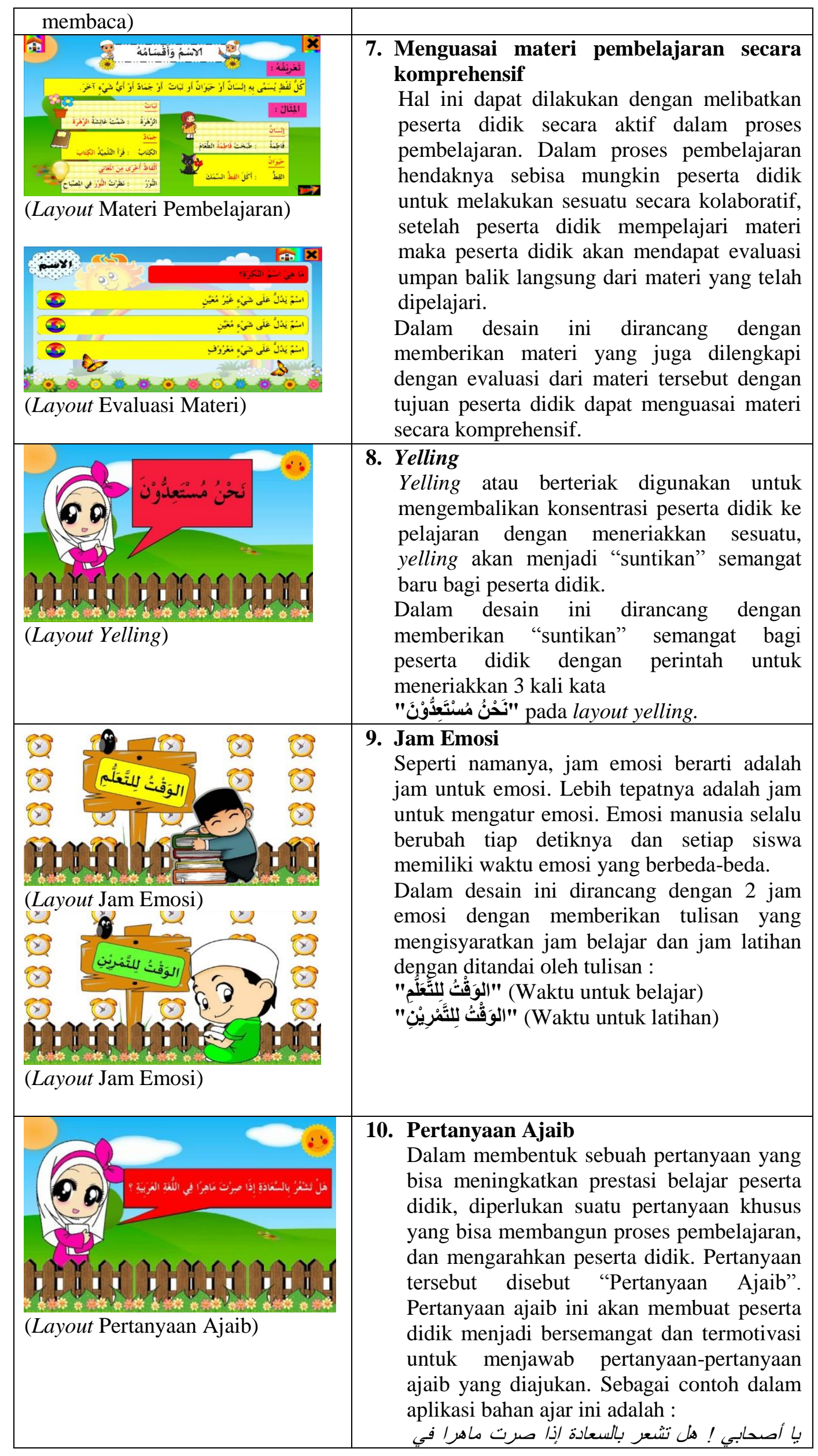




\begin{tabular}{|c|c|}
\hline & 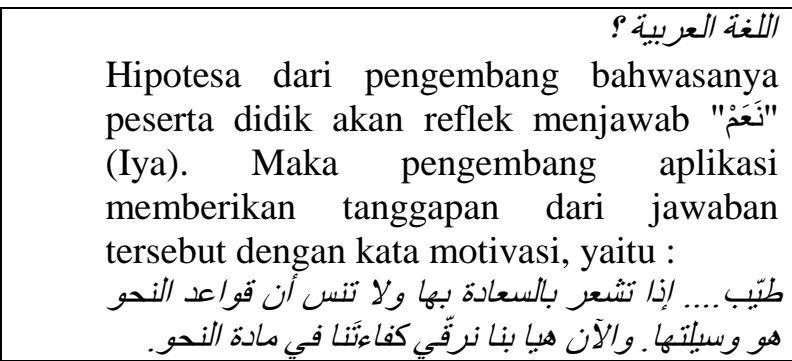 \\
\hline
\end{tabular}

Bahan ajar Interaktif ini bersifat aktif, maksudnya ia didesain agar dapat melakukan perintah balik kepada pengguna untuk melakukan suatu aktifitas. Dalam merancang bahan ajar interaktif berbasis aplikasi android ini, pengguna (mahasiswa/i) dibuat terlibat interaksi dua arah dengan bahan ajar yang sedang dipelajari dengan metode hypnoteaching.

2. Kelebihan Dan Kekurangan Dari Implementasi Pembelajaran Bahasa Arab Berbasis Multikulturalisme Agama Melalui Metode Hypnoteaching

\section{a. Kelebihan}

1) Kontinuitas

Keterpaduan keterampilan berbahasa akan menghasilkan kontinuitas dalam suatu program pengajaran dan pembelajaran. Tugas atau aktifitas berbahasa tidak dilakukan secara terpisah, tetapi berkaitan antara satu dengan yang lain dan saling tergantung antara satu dengan yang lain. Dari contoh rangkaian aktifitas di atas, misalnya mahasiswa/i akan berhasil dengan baik mengerjakan tugas writing/insyâ $\hat{~}^{\prime}$ setelah melalui berbagai persiapan dari aktifitas sebelumnya. Sejalan dengan itu kegiatan No.5 juga merupakan konsolidasi dan reinforcement berbahasa yang telah dipraktekkan pada rangkaian sebelumnya.

2) Input sebelum Output

Pengajaran bahasa arab berbasis Multikulturalisme Agama melalui metode Hypnoteaching ini akan memastikan bahwa ada input sebelum output pengajaran bahasa. Dalam pendekatan keterampilan berbahasa terpadu ini, pembelajar bisa diberikan input yang sesuai. Bisa jadi input tersebut dalam bentuk model atau contoh langsung sebagaimana tersebut di atas atau hanya berupa stimulus yang bebas. Input ini pada gilirannya akan menjadi dasar atau pondasi bagi pembelajar untuk menciptakan output belajar mereka sendiri (productive use of the language) dalam rangkaian tugas pembelajaran. Dengan demikian, maka strategi pengajaran sistem terpadu menekankan pada hubungan complementer antar listening dan speaking dan reading atau writing. Akhirnya hal ini akan membantu untuk meningkatkan pengajaran atau pembelajaran bagi keterampilan setiap pembelajar.

3) Realistik

Pengajaran skill terpadu ini akan mengembangkan empat skill berbahasa dalam framework yang natural, realistik, dan komunikatif. Pengguanaan framework semacam ini pada akhirnya akan membantu menumbuhkan kesadaran pembelajar atau mahasiswa tidak hanya pada bagaimana skill yang berbeda saling berkaitan dengan kebutuhan komunikasi, tetapi juga bagaimana empat keterampilan bahasa tersebut secara alami berhubungan satu dengan yang lain dalam realitas kehidupan.

4) Pikiran mahasiswa/i menjadi lebih rileks, nyaman, meditatif, terkendali,dan fokus Metode Hypnoteaching yang digunakan pembelajaran bahasa Arab ini dapat memudahkan siswa untuk mempelajari dan menyerap segala informasi yang tersedia dengan mempertimbangkan perkembangan kognitif dan dapat menciptakan kondisi sugestif. Metode ini memudahkan seseorang untuk menyerap informasi secara cepat tanpa adanya tekanan, ego, dan kecemasan atau dapat dikatakan apabila seseorang masuk dalam kondisi hipnosis maka semakin orang tersebut akan semakin sugestif.

\section{b. Kekurangan}

1) Urutan keterampilan bahasa yang kurang sistematis 
Pertama, sebaiknya keterampilan mendengar didahulukan daripada keterampilan berbicara dan keterampilan membaca didahulukan daripada menulis. Hal ini bertujuan agar mahasiswa/i mendapatkan masukan keterampilan receptive sebelum mereka menguasai keterampilan productive. Menurut Krahsen, mendahulukan kegiatan reseptif di dalam belajar bahasa Arab tampaknya lebih menjanjikan hasil yang memuaskan dari pada memaksa belajar sejak awal memproduksi kalimat bahasa Arab dimulai dengan memahami terlebih dulu, baik bahasa lisan maupun tulisan, atau salah satu di antaranya.

Kedua, keterampilan menulis sebaiknya menjadi urutan yang terakhir dalam pengajaran bahasa. Dengan begitu kemampuan menulis akan menjadi acuan untuk menyimpulkan dan memberikan penguatan terhadap aktifitas kebahasaan yang telah dilakukan sebelumnya.

2) Langkah metode hypnoteaching yang kurang lengkap

Dalam hypnoteaching ada beberapa langkah yang perlu dilakukan oleh guru. Langkah-langkah tersebut yaitu niat dan motivasi dalam diri, pacing, leading, menggunakan kata-kata positif, mengajar dan memberikan pujian, modeling, menguasai materi pembelajaran secara komprehensif, yelling, jam Emosi, pertanyaan ajaib. Sedangkan pada kegiatan pembelajaran bahasa Arab berbasis Multikulturalisme Agama melalui metode Hypnoteaching di Institut Dirosat Islamiyah Al-amien (IDIA) Fakultas Ushuluddin belum sepenuhnya lengkap dalam penerapan metode Hypnoteaching didalamnya, sebagai contoh : penerapan yelling, jam emosi dan pertanyaan ajaib. Dengan ini membuat cakupan tujuan dari metode hypnoteaching tersebut kurang

\section{SIMPULAN} lengkap dalam mencetak gol yang dituju.

Dari hasil paparan penelitian diatas dapat disimpulkan bahwa implementasi pembelajaran bahasa Arab berbasis multikulturalisme agama melalui metode hypnoteaching di Institut Dirosat Islamiyah Al-amien (IDIA) Fakultas Ushuluddin ini menuntut mahasiswa/i untuk mempraktekkan keterampilan-keterampilan dalam rangkaian yang tidak terputus-putus. Sehingga pada akhirnya pengajaran bahasa akan menjadi aktif dan komunikatif. Pengajaran bahasa yang aktif adalah sebuah pengajaran bahasa dimana mahasiswa/i aktif dalam setiap proses pengajaran dan aktif dalam mempraktekkan skill-skill kebahasaan. Mahasiswa/i mampu mengomunikasikan ide, keinginan, dengan menggunakan struktur bahasa dan ungkapan yang yang sesuai dengan maksud dan keinginan mereka.

\section{DAFTAR PUSTAKA}

A. Banks,James.(ed),Handbook of ResearchonMulticuturalEducation. San Francisco: JosseyBass, 2001.

Aqib Z. \& Murtadlo A. Kumpulan metode pembelajaran kreatif dan inovatif . Bandung: PT Sarana Tutorial Nuraini Sejahtera, 2016.

Ar Rikabi, Jawdat. Turuqu Tadris al Lughat al Arabiyah. Dimasyq: Dar al Fikr, 1986.

Baidhawy, Zakiyyudin. Pendidikan Agama Berwawasan Multikulturalisme. Jakarta: Erlangga, 2005.

H Tilaar, .A.R. Multikulturalisme; Tantangan-tantangan Global Masa Depan dalam Transformasi Pendidikan Nasional. Jakarta: Grasindo, 2004.

Hilmy, Masdar. Melembagakan Dialog (antar teks) agama, Kompas. Jakarta: 5 April 2002.

Ibrahim, R dan Nana Syaodih. Perencanaan Pengajaran. Jakarta: Rineka Cipta, 2002.

Iskandar, Metodologi Penelitian Kualitatif. Jakarta: Gaung Persada, 2009.

Jaya, Novian Triwidia. Hypnoteaching : Bukan Sekadar Mengajar. Bekasi : D-Brain, 2010.

Kamus Bahasa Indonesia, Kamus Pusat Bahasa. Jakarta: Pusat Bahasa, 2008.

Majid, Abdul. Strategi Pembelajaran. Bandung: Remaja Rosdakarya, 2013.

Mansur, Mohammad. Materi Bahasa Arab I MKMP 3212/4 Bahan ajar 1. Jakarta: Direktorat Jenderal Pembinaan Kelembagaan Agama Islam dan Universitas Terbuka, 1985.

Yustisia, N. Hypnoteaching : Seni ajar Mengeksplorasi Otak Peserta Didik. Jogjakarta : ARRuzz Media, 2012. 